\title{
High number of CD45RO+ tumor infiltrating lymphocytes is an independent prognostic factor in non-metastasized (stage I-IIA) esophageal adenocarcinoma
}

Sandra Rauser ${ }^{1 \dagger}$, Rupert Langer ${ }^{2 \dagger}$, Sebastian Tschernitz ${ }^{1}$, Peter Gais ${ }^{1}$, Uta Jütting ${ }^{3}$, Marcus Feith ${ }^{4}$, Heinz Höfler ${ }^{1,2}$, Axel Walch ${ }^{*}$

\begin{abstract}
Background: The validation of novel prognostic indicators is of greatest interest for the management of esophageal adenocarcinoma (Barrett's cancer), particularly for non-metastasized (stage I-IIA) disease. The prognostic role of tumor infiltrating T-lymphocytes (TILs) in Barrett's cancer has not been reported so far. Here we evaluated the impact of TILs on survival, recurrence, and metastasis in Barrett's cancer, particularly in stage I-IIA patients.

Methods: The levels of the adaptive immune markers CD3, CD8, and CD45RO were analyzed by immunohistochemistry and image analysis in tissue microarrays consisting of tumor tissues of 118 patients with primary resected Barrett's cancer. The findings were correlated with clinicopathological parameters including patient outcome.

Results: In multivariate analysis, a low density of intratumoral CD45RO+ immune cells was an independent unfavorable factor for disease-free survival in stages I-IIA patients $(P=0.004, \mathrm{RR}=4.7,95 \% \mathrm{Cl}=1.6-13.5)$ as well in the entire cohort $(P=0.048, \mathrm{RR}=2.0,95 \% \mathrm{Cl}=1.0-4.0)$. High CD3+ and CD45RO+ levels were associated with prolonged disease-free survival and overall survival as well with low recurrence rates of disease $(P=0.005$ and $P=$ 0.018 , respectively). In addition, low CD3+ levels were correlated with a higher frequency of lymph node metastasis $(P=0.025)$.

Conclusions: This study demonstrates that the density of CD45RO+ TILS is an independent prognostic factor in non-metastasized (stage I-IIA) Barrett's cancer patients and indicates an important role for the adaptive immunologic microenvironment. The inclusion of $\mathrm{CD} 45 \mathrm{RO}+$ density may help to improve the management of stage I-IIA Barrett's cancer.
\end{abstract}

\section{Background}

Barrett's cancer (esophageal adenocarcinoma), most frequently arising from intestinal metaplasia, has rapidly increased in incidence over the last decades, faster than any other gastrointestinal malignancy $[1,2]$. Despite advances in the therapy of locally advanced tumors with multimodal treatment strategies including neoadjuvant chemo- or radiochemotherapy [3-5], it still remains one of

\footnotetext{
* Correspondence: axel.walch@helmholtz-muenchen.de

† Contributed equally

'Institute of Pathology, Helmholtz Zentrum München, German Research Center for Environmental Health, Ingolstaedter Landstr. 1, 85764 Neuherberg, Germany

Full list of author information is available at the end of the article
}

the most deadly tumors in solid oncology. Therefore, there is the need of prognostic factors for improved individualized risk stratifications, and alternative treatment options, like targeted or immunologic therapeutic approaches.

Growth regulation and progression of cancer are not only influenced by the biological behavior of the tumor but also by the host defense mechanisms. Host immunity consists of a complex network of humoral and cellular components that interact with tumor cells and tumor stroma. On the cellular level, inflammatory elements encompass dendritic cells, macrophages, granulocytes and lymphocytes. Activated, memory- and cytotoxic tumor infiltrating T-lymphocytes (TILs) are considered
C Biomed Central

C 2010 Rauser et al; licensee BioMed Central Ltd. This is an Open Access article distributed under the terms of the Creative Commons Attribution License (http://creativecommons.org/licenses/by/2.0), which permits unrestricted use, distribution, and reproduction in any medium, provided the original work is properly cited. 
to be manifestations of a specific host immune reaction against cancer cells, related to the cytotoxic activity and the production of growth modulating cytokines of TIL [6,7]. Several studies have demonstrated the presence of TILs in various solid human cancers, most recently showing the association of an abundance of CD3+, CD8+ or CD45RO+ lymphocytic tumor infiltration with a survival benefit for patients with gastric [8] and colorectal [9-11] cancer, as well as for patients with endometrial [12], cervical [13], ovarian [14,15], urothelial [16] and hepatocellular [17] carcinoma and melanoma [18]. Furthermore, it was argued that the type, density, and location of immune cells in colorectal cancer have prognostic values that are superior to and independent of those of the UICC-TNM classification [10,19]. However, the effect of TILs in the clinical course of Barrett's cancer is largely unknown. The validation of novel prognostic indicators are therefore of greatest interest for the management of esophageal adenocarcinoma, particularly for non-metastasized (stage I-IIA) disease.

The aim of this study was to evaluate the impact of TILs on survival, recurrence, and metastasis in primary resected Barrett's cancer, particularly in non-metastasized (stage I-IIA) patients.

\section{Methods}

\section{Patient material}

In total, 118 patients with adenocarcinomas of the distal esophagus [(Barrett's cancer associated with histopathologically identified Barrett's esophagus (according to WHO 2000)] [20] were enrolled into this study. The patients had undergone primary surgical resection without chemo- or radiotherapy at the Department of Surgery, Klinikum rechts der Isar, Technische Universität München between 1991 and 2004. For all patients formalin-fixed paraffin-embedded tissue from surgical resection was available and individual patient data including outcome were acquired with approval from the ethics committee of the Technische Universität München. All tumor tissue specimens were procured from patients giving written informed consent.

Mean age of the patients was 63.6 years (range, 3383). Female/male ratio was $9 / 109.47$ tumors were UICC stage I, 18 stage IIA, 16 stage IIB, 28 stage III, and 8 stage IV. Lymph node metastases were absent in 65 cases (pNOM0) and present in 51 cases (pN1M0/1). The medium follow-up of the patients was 33 months for overall (range: 0.8 to 164 months) and 31 months for disease-free survival (range: 1.6 to 164 months).

\section{Tissue microarrays}

Using a tissue microarray instrument (Beecher Instruments, Sun Prairie, Wisconsin, USA), three representative areas of each tumor (1.0 $\mathrm{mm}$ diameter $)$ were removed from paraffin-embedded tissue blocks which had been prepared at the time of resection. Serial sections were cut for the purpose of immunohistochemistry and transferred to adhesive slides using the "paraffintape-transfer-system" according to manufacturer's instructions (Instrumedics, Hackensack, NJ, USA).

\section{Immunohistochemistry}

Immunohistochemical stainings for $\mathrm{CD} 3, \mathrm{CD} 8$, and CD45RO were carried out using an automated stainer (Ventana Discovery, Tuscon, AZ, USA) and DAB Map kit (Ventana). Monoclonal antibodies against CD3 (total T-cell marker; NeoMarkers, Fremont, CA, USA) were used in dilution at 1:100, against CD8 (cytotoxic T-cell marker; Dako, Hamburg, Germany) in dilution at 1:50 and against CD45RO (memory T-cell marker; Dako, Hamburg, Germany) in dilution at 1:1200.

\section{Image analysis}

Slides were analyzed with the use of an image-analysis workstation (SAMBA microscopic image processor; Meylan, France), the hardware and software of which have been first described by Brugal et al [21]. This system is fitted with a standard orthoplan microscope (Leica, Bensheim, Germany) and a colour TV-camera (JVC (KY-F30), 3-CCD, Tokyo, Japan). T-cells were analyzed in at least 10 randomly selected high-power fields (magnification $\mathrm{x} 400$ with the Leica microscope). Formal scoring (labeling index) for each antibody was then performed in one section for each TMA block. A labeling index resulted from the percentage of nuclear immunopositive area in relation to the total nuclear area of infiltrative tumor cells within the tissue. For feature extraction we applied the software running on SAMBA system [22].

\section{Statistical Analysis}

Receiver operating characteristic (ROC) analyses were done to determine cut-off levels for labeling indices of TILs (CD3, CD8, CD45RO positive lymphocytes) that correlate with clinical outcome (overall survival). The optimization of the cut-off determination was done by significance. All cases were therefore classified into lowand high-density groups for each marker, that is CD3+ low, CD8+ low, and CD45RO+ low (low-density groups) and CD3+ high, CD8+ high, and CD45RO+ high (highdensity groups). Correlations between parameters were performed using the Pearson's correlation for continuous variables, and for discrete variables the Chi square test or Fisher's exact test was used. Disease-free survival and overall survival were calculated from the date of surgical resection to the date of first recurrence, death, or last follow-up and the rates were determined according to the Kaplan-Meier method. Comparisons of 
survival curves were made using the log-rank test and multivariate analyses were done using the stepwise Cox regression analysis. Hazard ratios (risk ratios) were calculated univariate and multivariate and listed together with the confidence intervals. $P$ values $<0.05$ were considered statistically significant in all analyses, whereas $P$ values of 0.05 to 0.1 were considered as trend. All statistical analyses were done using the SAS (SAS Institute, Cary, NC, USA) software package.

\section{Results}

\section{Tumor infiltrating lymphocytes (TILs)}

Immunohistochemical stainings were available for CD3 in 99 cases, for CD8 in 107 cases, and for CD45RO in 110 cases. Labeling indices of $\mathrm{CD} 3+$ ranged from 0.3 18.8 (mean 5.65), of CD8+ from 0.01-6.2 (mean 0.9) and of CD45RO+ levels from 0-32.1 (mean 2.1). There was a significant correlation between the TIL levels of CD3+ and CD8+ TILs $(P<0.001 ; \mathrm{r}=0.54), \mathrm{CD} 3+$ and CD45RO+ TILs $(P<0.001, \mathrm{r}=0.4)$ and CD8+ and CD45RO+ TILs $(P<0.001 ; r=0.53)$. Cut-off levels with prognostic relevance were 0.9 for $\mathrm{CD} 3+, 0.5$ for $\mathrm{CD} 8+$ and 2.0 for CD45RO+.

\section{Correlation between clinicopathologic features and TIL density}

The clinical and pathological characteristics of the patients grouped by TIL density are summarized in Table 1. The CD3+ low group showed a higher frequency of lymph node metastasis than the corresponding high group $(P=0.025)$. Moreover, high $C D 3+$ and high $\mathrm{CD} 45 \mathrm{RO}+$ levels were associated with less recurrence of disease $(P=0.005$ and $P=0.018$, respectively). A low density of CD3+ showed a trend with higher stages of UICC classification $(P=0.086)$. Nevertheless, by building the two groups of the early stages I-IIA versus the late stages IIB-IV within the UICC classification, a high level of CD3+ immune cells were significantly associated with early stages $(P=0.025)$. Furthermore, low levels of CD45RO+ immune cells showed a trend for an association with a higher frequency of lymph node metastasis $(P=0.065)$, and grading $(P=0.091)$. Apart from that there was no correlation of levels of TILs with the pT category, distant metastasis, grading and UICC classification.

CD3+ and CD45RO+ TILs as predictors of patient survival In Kaplan-Meier survival analysis, a correlation between higher infiltration levels and survival was observed for CD3+ and CD45RO+ lymphocytes, but not for CD8+ lymphocytes (Figure 1). There were significant differences in disease-free survival between patients with high CD3+ levels and low CD3+ levels (median 30.6 months versus 21.4 months $)(P=0.014)$, as well between patients with high $\mathrm{CD} 45 \mathrm{RO}+$ densities and low CD45RO+ densities (median 31.7 months versus 13.2 months, $P=0.005$ ) (Figure $1 \mathrm{~A}-\mathrm{C}$ ). Similar results were observed for overall survival: CD3+ high and CD45RO+ high groups had a more favorable outcome than the corresponding low groups (median CD3+ high: 33.0 months versus CD3+ low 25.1 months, median CD45RO + high: 33.0 months versus 13.6 months $)(P=0.010$ each) (Figure 1D-F).

Univariate Cox proportional regression hazard models for disease-free survival showed a relative risk (RR) of 2.39 for patients whose tumors had a low density of CD45RO+ cells $(95 \%$ confidence interval $[\mathrm{CI}]=1.28$ 4.46, $P=0.007$ ) (overall survival: $\mathrm{RR}=2.28,95 \% \mathrm{CI}=$ 1.19-4.35, $P=0.013)$. Relative risks for disease-free and overall survival for patients with low densities of CD3+ were $1.96(95 \% \mathrm{CI}=1.13-3.39, P=0.016)$ and $2.06(95 \%$ $\mathrm{CI}=1.18-3.61, P=0.012)$, respectively.

We also found that the combined influence of high densities of $\mathrm{CD} 3+\mathrm{CD} 8+\mathrm{CD} 45 \mathrm{RO}+$ cells resulted in an improved disease-free $(P=0.017)$ and overall survival $(P$ $=0.015)$ as compared to low levels of CD3+CD8 $+\mathrm{CD} 45 \mathrm{RO}+$ (Figure 2). In the group of the patients with high levels of CD3+CD8+CD45RO+ TILs median disease-free survival time was 29.0 months as compared to 14.6 months for patients with low densities of combined $\mathrm{CD} 3+\mathrm{CD} 8+\mathrm{CD} 45 \mathrm{RO}+$ cells (overall survival: 33.0 versus 17.7 months) (Figure 2). There was also a statistically significant prolonged survival, when high densities of $\mathrm{CD} 3+\mathrm{CD} 45 \mathrm{RO}+$ cells were combined (disease-free survival $P=0.004$, overall survival $P=0.007)$. $P$-values for the combination of CD3+CD8+ cells were $P=0.055$ for disease-free survival and $P=0.029$ for overall survival. For the combination of CD8+CD45RO+ cells there was a trend in prolonged survival (disease-free and overall survival each $P=0.059$ ).

Remarkably, in multivariate Cox regression analysis a high infiltration level of CD45RO+ lymphocytes was a significant independent prognostic factor beside $\mathrm{pN}$ and $M$-category as well for disease-free survival $(P=$ $0.048)$ as for overall survival $(P=0.028)$ (Table 2$)$. Expression patterns of CD8+ and CD45RO+ TILs had no independent prognostic value, nor did the combination of CD3+CD8+CD45RO+ TILs.

\section{TIL as a predictor of regional lymph node metastasis}

Disease-free and overall patient survival correlated with a high density of CD45RO+ TILs in pN0 patients, but not in $\mathrm{pN} 1$ patients (Figure 3). pN0 patients with a high density of CD45RO+ cells had a significant more favorable outcome than did patients with low CD45RO+ levels (disease-free survival: $P=0.001$, overall survival: $P$ 
Table 1 Clinical and pathological characteristics of the patients grouped by TIL density

\begin{tabular}{|c|c|c|c|c|c|c|c|c|c|}
\hline \multirow[b]{2}{*}{ Characteristics } & \multicolumn{3}{|c|}{$\begin{array}{c}C D 3+\mathrm{TIL} \\
\mathrm{n}=99\end{array}$} & \multicolumn{3}{|c|}{$\begin{array}{c}C D 8+\text { TIL } \\
n=107\end{array}$} & \multicolumn{3}{|c|}{$\begin{array}{c}\text { CD45RO+ TIL } \\
n=110\end{array}$} \\
\hline & low & high & $P$-value & low & high & $P$-value & low & high & $P$-value \\
\hline Total number of patients & $42(42.4 \%)$ & $57(57.6 \%)$ & & $50(46.7 \%)$ & $57(53.3 \%)$ & & $17(15.5 \%)$ & $93(84.5 \%)$ & \\
\hline Gender & & & 0.453 & & & 1.0 & & & 0.607 \\
\hline male & 38 (38.4\%) & $54(54.5 \%)$ & & $46(43.0 \%)$ & $53(49.5 \%)$ & & $15(13.6 \%)$ & 87 (79.1\%) & \\
\hline female & $4(4.0 \%)$ & $3(3.0 \%)$ & & $4(3.7 \%)$ & $4(3.7 \%)$ & & $2(1.8 \%)$ & $6(5.5 \%)$ & \\
\hline Tumour stage & & & 0.298 & & & 0.688 & & & 0.353 \\
\hline pT1 & 15 (15.3\%) & $26(26.5 \%)$ & & $20(18.9 \%)$ & $25(23.6 \%)$ & & $6(5.5 \%)$ & $42(38.5 \%)$ & \\
\hline pT2 & $7(7.1 \%)$ & $12(12.2 \%)$ & & $9(8.5 \%)$ & $12(11.3 \%)$ & & $2(1.8 \%)$ & $18(16.5 \%)$ & \\
\hline pT3 & $20(20.4 \%)$ & $18(18.4 \%)$ & & $21(19.8 \%)$ & 19 (17.9\%) & & $9(8.3 \%)$ & $32(29.4 \%)$ & \\
\hline Lymph node metastasis & & & 0.025 & & & 0.440 & & & 0.065 \\
\hline pNO & 17 (17.3\%) & $35(35.7 \%)$ & & $26(24.5 \%)$ & $31(29.2 \%)$ & & $6(5.5 \%)$ & $54(49.5 \%)$ & \\
\hline pN1 & $25(25.5 \%)$ & $21(21.4 \%)$ & & $24(22.6 \%)$ & $25(23.6 \%)$ & & $11(10.1 \%)$ & $38(34.9 \%)$ & \\
\hline Distant metastasis & & & 0.212 & & & 0.428 & & & 0.108 \\
\hline Mo & 37 (37.8\%) & $53(54.1 \%)$ & & $45(42.5 \%)$ & $52(49.1 \%)$ & & $14(12.8 \%)$ & 87 (79.8\%) & \\
\hline M1 & $5(5.1 \%)$ & $3(3.1 \%)$ & & $5(4.7 \%)$ & $4(3.8 \%)$ & & $3(2.8 \%)$ & $5(4.6 \%)$ & \\
\hline Residual tumour & & & 0.070 & & & 0.276 & & & 0.125 \\
\hline Ro & $33(34.4 \%)$ & $51(53.1 \%)$ & & 41 (39.4\%) & 51 (49.0\%) & & $13(12.1 \%)$ & 81 (75.7\%) & \\
\hline R1 & $8(8.3 \%)$ & $4(4.2 \%)$ & & $7(6.7 \%)$ & $5(4.8 \%)$ & & $4(3.7 \%)$ & $9(8.4 \%)$ & \\
\hline Grading & & & 0.273 & & & 0.696 & & & 0.091 \\
\hline G1 & $0(0.0 \%)$ & $2(2.1 \%)$ & & $2(1.9 \%)$ & $1(1.0 \%)$ & & $0(0.0 \%)$ & $5(4.6 \%)$ & \\
\hline G2 & $17(17.5 \%)$ & $27(27.8 \%)$ & & $20(19.0 \%)$ & $26(24.8 \%)$ & & $4(3.7 \%)$ & 42 (38.9\%) & \\
\hline G3 & $25(25.8 \%)$ & $26(26.8 \%)$ & & $27(25.7 \%)$ & $29(27.6 \%)$ & & $13(12.0 \%)$ & 44 (40.7\%) & \\
\hline UICC classification & & & 0.086 & & & 0.776 & & & 0.156 \\
\hline I & $11(11.2 \%)$ & $24(24.5 \%)$ & & $16(15.1 \%)$ & $23(21.7 \%)$ & & $4(3.7 \%)$ & 38 (34.9\%) & \\
\hline II & $11(11.2 \%)$ & 19 (19.4\%) & & $16(15.1 \%)$ & $17(16.0 \%)$ & & $4(3.7 \%)$ & $28(25.7 \%)$ & \\
\hline III & $15(15.3 \%)$ & $10(10.2 \%)$ & & $14(13.2 \%)$ & $12(11.3 \%)$ & & $6(5.5 \%)$ & $21(19.3 \%)$ & \\
\hline IV & $5(5.1 \%)$ & $3(3.1 \%)$ & & $4(3.8 \%)$ & $4(3.8 \%)$ & & $3(2.8 \%)$ & $5(4.6 \%)$ & \\
\hline Recurrence of disease & & & 0.005 & & & 0.209 & & & 0.018 \\
\hline No & $13(13.3 \%)$ & $33(33.7 \%)$ & & $21(19.8 \%)$ & $30(28.3 \%)$ & & $4(3.7 \%)$ & 50 (45.9\%) & \\
\hline Yes & 29 (29.6\%) & $23(23.5 \%)$ & & $28(26.4 \%)$ & 27 (25.5\%) & & 13 (11.9\%) & 42 (38.5\%) & \\
\hline
\end{tabular}

$=0.041$ ) (Figure 3A and 3C). In contrast, patients with lymph node metastasis ( $\mathrm{pN} 1$ ) did not benefit from a high CD45RO+ level. There was no statistically significant difference between CD45RO+ levels and survival in pN1 patients (disease-free survival: $P=0.721$, overall survival: $P=0.399$ ) (Figure $3 \mathrm{~B}$ and $3 \mathrm{D}$ ).

Multivariate Cox regression analysis within the pNOgroup revealed that low densities of CD45RO+ cells were independently associated with an unfavorable disease-free survival $(P=0.004, \mathrm{RR}=4.7,95 \% \mathrm{CI}=1.6$ 13.5) (Table 2). In $\mathrm{pN} 1$ patients, distant metastasis was an independent prognostic factor $(P=0.002, \mathrm{RR}=3.6$, 95\% CI $=1.6-8.0)$.

Furthermore, the CD3+ low group showed a higher frequency of lymph node metastasis than the corresponding high group $(P=0.025)$ and for the CD45RO+ low group there was a trend for a higher presence of lymph node metastases $(P=0.065)$ (Table 1$)$. 

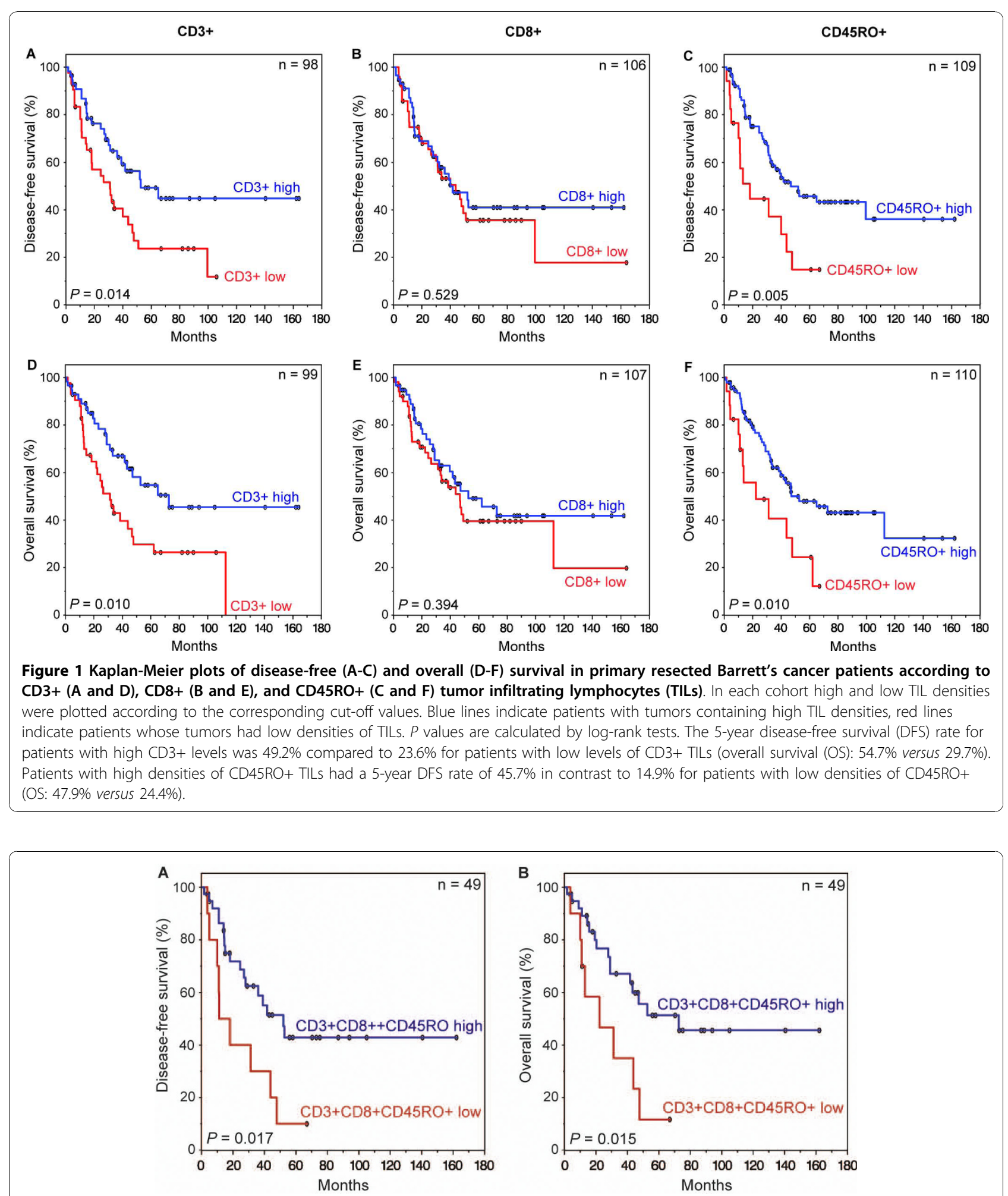

Figure 2 Kaplan-Meier plots of disease-free (A) and overall (B) survival in primary resected Barrett's cancer patients as a function of tumor infiltrating lymphocyte (TIL) density. Survival differences were found when high and low densities of CD3+, CD8+, and CD45RO+ were combined. In each cohort high and low TIL densities were plotted according to the corresponding cut-off values. Blue lines indicate patients with tumors containing high $\mathrm{CD} 3+\mathrm{CD} 8+\mathrm{CD} 45 \mathrm{RO}+$ densities, red lines indicate patients whose tumors had low densities of $C D 3+C D 8$ + CD45RO+ TILs. $P$ values are calculated by log-rank tests. The 5-year disease-free survival rate for patients with high levels of CD3+CD8+CD45RO + TILs was $42.9 \%$ compared to $10.0 \%$ for patients with low levels of CD3+CD8+CD45RO+ TILs (overall survival: $51.3 \%$ versus $11.7 \%$ ). 
Table 2 Multivariate analyses

\begin{tabular}{|c|c|c|c|c|c|c|}
\hline \multirow[b]{2}{*}{ Variable } & \multicolumn{3}{|c|}{ Disease-free survival } & \multicolumn{3}{|c|}{ Overall survival } \\
\hline & $P$-value & RR & $95 \% \mathrm{Cl}$ & $P$-value & RR & $95 \% \mathrm{Cl}$ \\
\hline \multicolumn{7}{|l|}{ pNO patients } \\
\hline CD45RO+ (low) & 0.004 & 4.7 & $1.6-13.5$ & n. s. & & \\
\hline \multicolumn{7}{|l|}{ All patients } \\
\hline $\mathrm{pN}$ & $<0.0001$ & 4.7 & $2.5-9.0$ & $<0.0001$ & 4.6 & $2.4-8.8$ \\
\hline M & 0.011 & 3.1 & $1.3-7.3$ & 0.023 & 2.8 & $1.1-6.6$ \\
\hline CD45RO+ (low) & 0.048 & 2.0 & $1.0-4.0$ & 0.028 & 1.1 & $1.0-1.2$ \\
\hline
\end{tabular}

Abbreviations: $\mathrm{Cl}$, confidence interval; n.s., not significant; $\mathrm{RR}$, relative risk.

\section{Discussion}

In this study, we analyzed the impact of tumor infiltrating lymphocytes (TILs) on survival, recurrence, and metastasis in primary resected esophageal adenocarcinoma (Barrett's cancer), particularly in stage I-IIA patients. The presence of high numbers of CD45RO+ lymphocytes was an independent predictor of increased survival particularly in non-metastasized (stage I-IIA) patients as well in the entire cohort. A high CD3+ level was further associated with prolonged survival and the absence of regional lymph node metastasis. Moreover, high infiltration levels of CD45RO+ and CD3+ T-cells were correlated with a lower rate of recurrence.

Similar observations were made in different cancer types. A study on gastric cancer demonstrated the independent prognostic value of the density of $\mathrm{CD} 3+, \mathrm{CD} 8+$, and CD45RO+ lymphocytes for regional lymph node metastasis and patient survival [8]. Studies on colorectal cancer showed that TILs predict survival better than conventional anatomical staging and that a high density of CD45RO+ lymphocytes is correlated with the absence of lymphatic vessel invasion [10,11]. In melanoma patients it was found that brisk TIL infiltration in tumor predicts sentinel lymph node metastasis [18] and in early-stage cervical cancer it was demonstrated that a high number of intraepithelial CD8+ lymphocytes is associated with the absence of lymph node metastasis [13]. Also, in vivo experiments and animal models have provided data supporting the role of TILs in cancer immunosurveillance $[23,24]$. Although the influence of lymphocytic infiltration has been studied in squamous cell cancer (SCC) of the esophagus [25-27], so far less information is available about the role of TILs in adenocarcinomas of the esophagus (Barrett's cancer).

To our knowledge, the current study is the first one to examine the prognostic influence of intratumoral CD3+ total T-lymphocytes, CD8+ cytotoxic T-lymphocytes, and CD45RO+ memory T-lymphocytes in a large cohort of primary resected Barrett's cancer patients $(n=118)$. In a previous study of a smaller series of human esophageal carcinomas $(n=70)$, which encompassed both squamous cell carcinomas and adenocarcinomas, the presence of a dense intratumoral CD8+ lymphocytic infiltration was associated with good prognosis independent from tumor stage and nodal stage [28]. However, we did not find CD8+ TILs to be a prognostic factor in Barrett's cancer. A recent work with a cohort of 106 adenocarcinomas of the esophagus failed to show a prognostic influence of CD3+ and CD8+ TILs [29], whereas in our cohort patients benefit from a high CD3 + lymphocytic infiltration. A possible explanation may be different methods applied to quantify TILs. In the study of Schumacher et al the number of CD8+ lymphocytes was counted by fluorescence microscopy and individual cases were classified in groups according to their location and quantification [28]. Zingg et al used high power field light microscopy and assessed the number of lymphocytes in two different locations, at the periphery and in the center of the tumors [29]. In our study, we used tissue microarrays with core biopsies taken randomized from the tumor area and the quantification of lymphocytic infiltration was done by image analysis. This approach has been demonstrated to be representative and has been used in different types of cancer $[8-10,12,30]$.

Metastatic relapse attributable to the presence of tumor cells within lymph nodes is the most frequent cause leading to cancer-related death in patients with esophageal tumors [31]. In the current study, high levels of CD45RO+ TILs were significantly associated with improved survival in Barrett's cancer, on the one hand in the whole study cohort as well in the subgroup of non-metastasized patients. We also showed that high densities of CD45RO+ cells were an independent predictor of improved overall and disease-free survival. We found, that recurrence of disease less often occurred in the presence of high levels of CD45RO+ TILs. This observation is in line with the functional mechanism of memory $\mathrm{T}$-lymphocytes, namely providing a more rapid and effective secondary immune response to previously encountered antigens [32]. Our data suggest that CD45RO+ T-lymphocytes within esophageal adenocarcinomas function not only locally but also systemically in tumor-draining lymph nodes to suppress micrometastasis.

Our results show that the presence of intratumoral $\mathrm{CD} 45 \mathrm{RO}+\mathrm{T}$-cells is associated with the lack of tumor metastases in the lymph nodes of Barrett's cancer patients. Because the absence of lymph node metastases is strongly associated with a better prognosis, patients with high CD45RO+ lymphocyte levels are likely to display an improved clinical outcome in Barrett's cancer. 


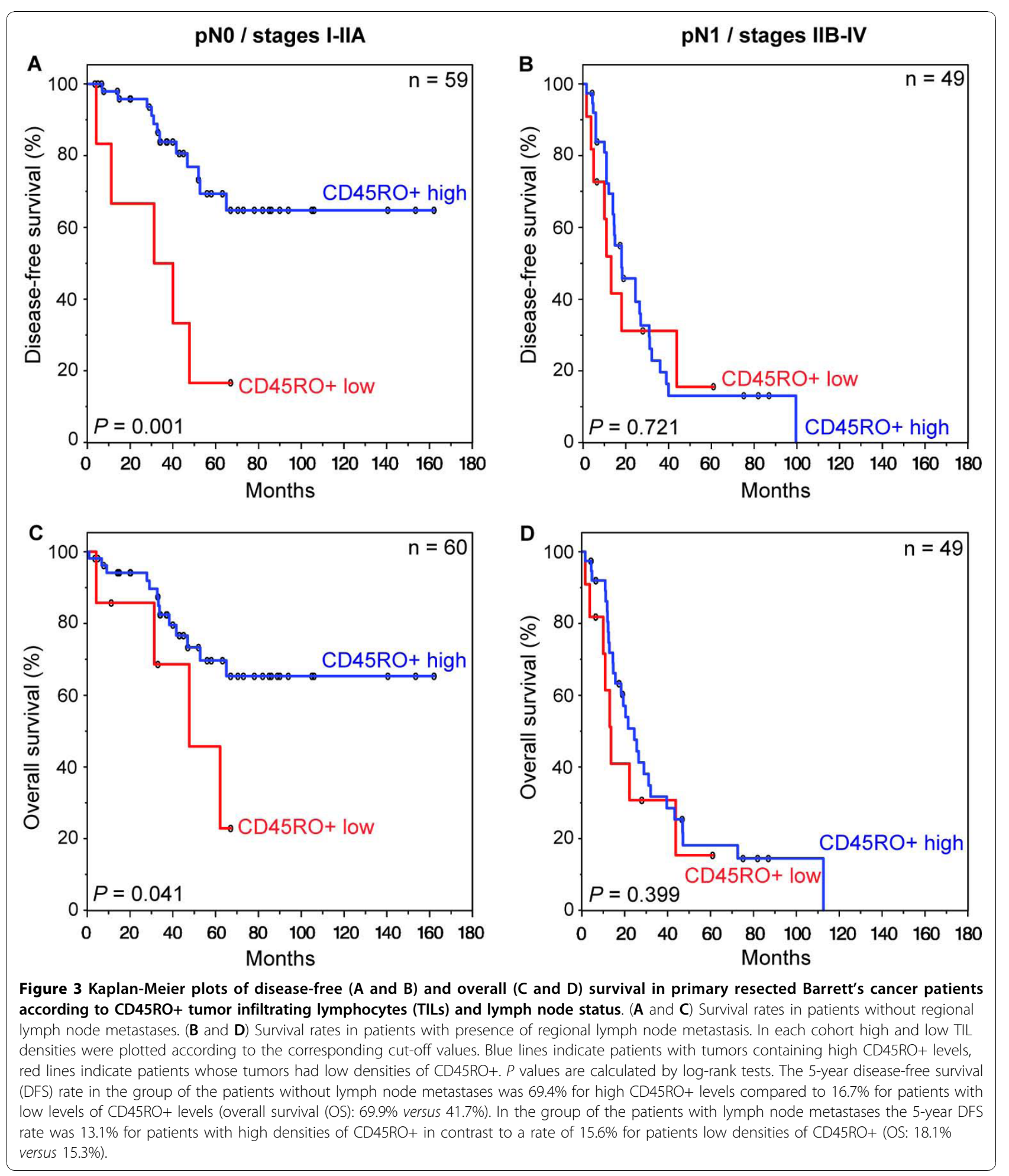

CD45RO+ and CD3+ TILs within Barrett's cancer may serve as criteria for selection and monitoring of patients for adjuvant immunotherapeutic strategies and can be a reliable prognostic marker to predict favorable outcome in patient subgroups. In our study, we focused on the
T-lymphocytic cellular component, but additional studies are in need to elucidate the mechanisms and potency of host immunity. This is in particular concern for the purpose of the development of potential immunomodulatory or targeted cancer therapies that are 
highly required for the treatment of esophageal adenocarcinoma due to its aggressive behavior and the limited success of conventional therapy regimes. Our findings may provide a basis for risk adopted tumor treatment through predicting clinical outcome and definition of patient subgroups with different prognosis. The inclusion of CD45RO+ TIL density may help to improve the prognostication of stage I-IIA Barrett's cancer. Moreover, our results may be highly valuable in the context of future promising adjuvant immunotherapy and for potential immunomodulatory targeted therapy approaches.

\section{Acknowledgements}

A. Walch acknowledges the financing support of the Deutsche Krebshilfe (108096) and the MolBioMed Programme (EndoMed 01EZ0802) of the BMBF, Germany.

We thank Ulrike Buchholz, Andrea Harwardt, Claudia-Mareike Pflüger, and Eleonore Samson for excellent technical assistance performing the laboratory work.

\section{Author details \\ 'Institute of Pathology, Helmholtz Zentrum München, German Research Center for Environmental Health, Ingolstaedter Landstr. 1, 85764 Neuherberg, Germany. ${ }^{2}$ Institute of Pathology, Technische Universität München, Ismaninger Str. 22, 81675 Munich, Germany. Institute of Biomathematics and Biometry, Helmholtz Zentrum München, German Research Center for Environmental Health, Ingolstaedter Landstr. 1, 85764 Neuherberg, Germany. ${ }^{4}$ Department of Surgery, Klinikum rechts der Isar, Technische Universität München, Ismaninger Str. 22, 81675 Munich, Germany.}

\section{Authors' contributions}

$\mathrm{SR}, \mathrm{RL}$ and AW interpreted the data and drafted the manuscript. RL carried out assembly of tissue microarrays. ST and PG carried out the evaluation of the immunohistochemical stainings and image analysis and helped to draft the manuscript. UJ performed the statistical analyses and interpreted the data. MF participated in the design of the study and was responsible for collection and interpretation of clinical data. SR, RL, HH and AW conceived of the study and participated in its design and coordination. All authors red and approved the final manuscript.

\section{Competing interests}

The authors declare that they have no competing interests.

Received: 11 May 2010 Accepted: 5 November 2010

Published: 5 November 2010

\section{References}

1. DeMeester SR: Adenocarcinoma of the esophagus and cardia: a review of the disease and its treatment. Ann Surg Oncol 2006, 13(1):12-30

2. Jemal A, Siegel $R$, Ward E, Hao Y, Xu J, Thun MJ: Cancer statistics, 2009. CA Cancer J Clin 2009, 59(4):225-249.

3. Cunningham D, Allum WH, Stenning SP, Thompson JN, Van de Velde CJ, Nicolson M, Scarffe JH, Lofts FJ, Falk SJ, Iveson TJ, Smith DB, Langley RE, Verma M, Weeden S, Chua YJ, MAGIC Trial Participants : Perioperative chemotherapy versus surgery alone for resectable gastroesophageal cancer. N Engl J Med 2006, 355(1):11-20.

4. Gebski V, Burmeister B, Smithers BM, Foo K, Zalcberg J, Simes J: Survival benefits from neoadjuvant chemoradiotherapy or chemotherapy in oesophageal carcinoma: a meta-analysis. Lancet Oncol 2007, 8(3):226-234.

5. Siewert JR, Lordick F, Ott K, Stein HJ, Weber WA, Becker K, Peschel C, Fink U, Schwaiger M: Induction chemotherapy in Barrett cancer: influence on surgical risk and outcome. Ann Surg 2007, 246(4):624-628, discussion 628-631.

6. Piersma SJ, Welters MJ, van der Burg SH: Tumor-specific regulatory T cells in cancer patients. Hum Immunol 2008, 69(4-5):241-249.
7. Yu P, Fu YX: Tumor-infiltrating T lymphocytes: friends or foes? Lab Invest 2006, 86(3):231-245.

8. Lee HE, Chae SW, Lee YJ, Kim MA, Lee HS, Lee BL, Kim WH: Prognostic implications of type and density of tumour-infiltrating lymphocytes in gastric cancer. Br J Cancer 2008, 99(10):1704-1711.

9. Pages F, Kirilovsky A, Mlecnik B, Asslaber M, Tosolini M, Bindea G, Lagorce C, Wind P, Marliot F, Bruneval P, Zatloukal K, Trajanoski Z, Berger A, Fridman WH, Galon J: In situ cytotoxic and memory T cells predict outcome in patients with early-stage colorectal cancer. J Clin Oncol 2009, 27(35):5944-5951.

10. Galon J, Costes A, Sanchez-Cabo F, Kirilovsky A, Mlecnik B, Lagorce-Pages C, Tosolini M, Camus M, Berger A, Wind P, Zinzindohoue F, Bruneval P, Cugnenc PH, Trajanoski Z, Fridman WH, Pages F: Type, density, and location of immune cells within human colorectal tumors predict clinical outcome. Science 2006, 313(5795):1960-1964.

11. Pages F, Berger A, Camus M, Sanchez-Cabo F, Costes A, Molidor R, Mlecnik B, Kirilovsky A, Nilsson M, Damotte D, Meatchi T, Bruneval P, Cugnenc PH, Trajanoski Z, Fridman WH, Galon J: Effector memory T cells, early metastasis, and survival in colorectal cancer. N Engl J Med 2005, 353(25):2654-2666.

12. de Jong RA, Leffers $\mathrm{N}$, Boezen $\mathrm{HM}$, ten Hoor KA, van der Zee $\mathrm{AG}$, Hollema H, Nijman HW: Presence of tumor-infiltrating lymphocytes is an independent prognostic factor in type I and II endometrial cancer. Gynecol Oncol 2009, 114(1):105-110.

13. Piersma SJ, Jordanova ES, van Poelgeest MI, Kwappenberg KM, van der Hulst JM, Drijfhout JW, Melief CJ, Kenter GG, Fleuren GJ, Offringa R, van der Burg SH: High number of intraepithelial CD8+ tumor-infiltrating lymphocytes is associated with the absence of lymph node metastases in patients with large early-stage cervical cancer. Cancer Res 2007, 67(1):354-361

14. Sato E, Olson SH, Ahn J, Bundy B, Nishikawa $H$, Qian F, Jungbluth AA, Frosina D, Gnjatic S, Ambrosone C, Kepner J, Odunsi T, Ritter G, Lele S, Chen YT, Ohtani H, Old L, Odunsi K: Intraepithelial CD8+ tumorinfiltrating lymphocytes and a high CD8+/regulatory $T$ cell ratio are associated with favorable prognosis in ovarian cancer. Proc Natl Acad SCi USA 2005, 102(51):18538-18543.

15. Zhang L, Conejo-Garcia JR, Katsaros D, Gimotty PA, Massobrio M, Regnani G, Makrigiannakis A, Gray H, Schlienger K, Liebman MN, Rubin SC, Coukos G: Intratumoral T cells, recurrence, and survival in epithelial ovarian cancer. N Engl J Med 2003, 348(3):203-213.

16. Sharma P, Shen Y, Wen S, Yamada S, Jungbluth AA, Gnjatic S, Bajorin DF, Reuter $V E$, Herr H, Old $\amalg$, Sato E: CD8 tumor-infiltrating lymphocytes are predictive of survival in muscle-invasive urothelial carcinoma. Proc Natl Acad Sci USA 2007, 104(10):3967-3972.

17. Gao Q, Qiu SJ, Fan J, Zhou J, Wang XY, Xiao YS, Xu Y, Li YW, Tang ZY: Intratumoral balance of regulatory and cytotoxic $T$ cells is associated with prognosis of hepatocellular carcinoma after resection. J Clin Oncol 2007, 25(18):2586-2593.

18. Taylor RC, Patel A, Panageas KS, Busam KJ, Brady MS: Tumor-infiltrating lymphocytes predict sentinel lymph node positivity in patients with cutaneous melanoma. J Clin Oncol 2007, 25(7):869-875.

19. Galon J, Fridman WH, Pages F: The adaptive immunologic microenvironment in colorectal cancer: a novel perspective. Cancer Res 2007, 67(5):1883-1886.

20. Werner M, Flejou JF, Hainaut P, Höfler H, Lambert R, Keller G, Stein HJ: Adenocarcinoma of the oesophagus. In World Health Organization Classification of Tumours Pathology and Genetics of Tumours of the Digestive System. Edited by: Hamilton SR, Aaltonen LA. Lyon: IARC Press; 2000:20-26.

21. Brugal G, Garbay C, Giroud F, Adelh D: A double scanning microphotometer for image analysis: hardware, software and biomedical applications. J Histochem Cytochem 1979, 27(1):144-152.

22. Mueller J, Werner M, Siewert JR: Malignant progression in Barrett's esophagus: pathology and molecular biology. Recent Results Cancer Res 2000, 155:29-41.

23. Dunn GP, Old $L$, Schreiber RD: The three Es of cancer immunoediting Annu Rev Immunol 2004, 22:329-360.

24. Dunn GP, Bruce AT, Ikeda H, Old LJ, Schreiber RD: Cancer immunoediting: from immunosurveillance to tumor escape. Nat Immunol 2002, 3(11):991-998.

25. Yoshioka T, Miyamoto M, Cho Y, Ishikawa K, Tsuchikawa T, Kadoya M, Li L, Mishra R, Ichinokawa K, Shoji Y, Matsumura Y, Shichinohe T, Hirano S, 
Shinohara T, Itoh T, Kondo S: Infiltrating regulatory T cell numbers is not a factor to predict patient's survival in oesophageal squamous cell carcinoma. Br J Cancer 2008, 98(7):1258-1263.

26. Cho Y, Miyamoto M, Kato K, Fukunaga A, Shichinohe T, Kawarada Y, Hida Y, Oshikiri T, Kurokawa T, Suzuoki M, Nakakubo Y, Hiraoka K, Murakami S, Shinohara T, Itoh T, Okushiba S, Kondo S, Katoh H: CD4+ and CD8+ T cells cooperate to improve prognosis of patients with esophageal squamous cell carcinoma. Cancer Res 2003, 63(7):1555-1559.

27. Ikeguchi M, Saito H, Katano K, Tsujitani S, Maeta M, Kaibara N: Correlation between the lymphocytic infiltration of tumors and the proliferative activity of cancer cells from surgically treated esophageal carcinoma. Oncology 1997, 54(4):311-317.

28. Schumacher K, Haensch W, Roefzaad C, Schlag PM: Prognostic significance of activated CD8(+) T cell infiltrations within esophageal carcinomas. Cancer Res 2001, 61(10):3932-3936.

29. Zingg U, Montani M, Frey DM, Dirnhofer S, Esterman AJ, Went P, Oertli D: Tumour-infiltrating lymphocytes and survival in patients with adenocarcinoma of the oesophagus. Eur J Surg Oncol 2010, 36(7):670-677.

30. Salama P, Phillips M, Grieu F, Morris M, Zeps N, Joseph D, Platell C, lacopetta $B$ : Tumor-infiltrating FOXP3+ T regulatory cells show strong prognostic significance in colorectal cancer. J Clin Oncol 2009, 27(2):186-192.

31. Izbicki JR, Hosch SB, Pichlmeier U, Rehders A, Busch C, Niendorf A Passlick B, Broelsch CE, Pantel K: Prognostic value of immunohistochemically identifiable tumor cells in lymph nodes of patients with completely resected esophageal cancer. N Engl J Med 1997, 337(17):1188-1194.

32. Sallusto F, Geginat J, Lanzavecchia A: Central memory and effector memory T cell subsets: function, generation, and maintenance. Annu Rev Immunol 2004, 22:745-763.

\section{Pre-publication history}

The pre-publication history for this paper can be accessed here: http://www.biomedcentral.com/1471-2407/10/608/prepub

doi:10.1186/1471-2407-10-608

Cite this article as: Rauser et al:: High number of CD45RO+ tumor infiltrating lymphocytes is an independent prognostic factor in nonmetastasized (stage I-IIA) esophageal adenocarcinoma. BMC Cancer 2010 10:608.

\section{Submit your next manuscript to BioMed Central} and take full advantage of:

- Convenient online submission

- Thorough peer review

- No space constraints or color figure charges

- Immediate publication on acceptance

- Inclusion in PubMed, CAS, Scopus and Google Scholar

- Research which is freely available for redistribution 